\title{
ANÁLISE SEMIÓTICA DE MAPAS DAS ELEIÇÕES PRESIDENCIAIS DE 2014: FRATURAS NO DISCURSO DA IDENTIDADE NACIONAL ${ }^{1}$
}

\author{
SEMIOTIC ANALYSIS OF THE PRESIDENTIAL ELECTIONS’ MAPS \\ FROM 2014: \\ FRACTURES IN THE DISCOURSE OF THE NATIONAL IDENTITY
}

\author{
Luiza Helena Oliveira da Silva ${ }^{2}$ \\ Univesidade Federal do Tocantins
}

\section{RESUMO}

Este trabalho analisa, sob a perspectiva da semiótica discursiva, suas produções relativas a uma semiótica do espaço e estudos sobre a identidade na contemporaneidade, seis dos muitos mapas divulgados na mídia digital e impressa imediatamente após o resultado das eleições para presidente do Brasil, nas votações em segundo turno, em outubro de 2014. Trazemos aqui linhas mestras de uma reflexão inicial sobre o modo de representar o país, recortando-o a partir das opções políticoideológicas. Entendemos os mapas como significantes a serem interpretados, enunciados que deixam ver, ainda que sob a aparência da referencialidade e do efeito de evidência, a perspectiva do enunciador que propõe uma percepção particular/social de uma fatia do mundo. Para isso ainda contam os enunciados que os acompanham, ao traduzirem em palavras os números das votações e, ao mesmo tempo, uma sanção sobre os resultados do pleito nacional.

PALAVRAS-CHAVE: identidade nacional; eleições presidenciais; discurso político; sociossemiótica

\begin{abstract}
This paper analyzes, from the perspective of discursive semiotics, mainly its productions related to a semiotics of space and studies on contemporary identity, six of the many maps published in the digital media and printed immediately after the result of the Brazilian presidential elections, in the voting of the second round, in October 2014. Here we draw the main lines of an initial reflection on how to represent the country, cutting it from the political-ideological options. We understand maps as signifiers to be interpreted, statements that show, even under the appearance of referentiality and the effect of evidence, the perspective of the enunciator that enunciates a particular/social perception of a slice of the world. To this end, they also count the statements that accompany them, by translating the numbers of the votes into words and, at the same time, a sanction about the results of the national lawsuit.
\end{abstract}

KEYWORDS: national identity ; presidential elections ; politic discourse ; sociosemiotic

\section{SENTIDOS DE (DES)PERTENCIMENTO}

Principiemos com a citação de um poema de Mário de Andrade, Descobrimento:

Abancado à escrivaninha em São Paulo

\footnotetext{
${ }^{1}$ Uma versão deste trabalho foi apresentada em comunicação online no STIS - Seminários Teóricos Interdisciplinares do SEMIOTEC (UFMG), em maio de 2017.

2 Professora do Programa de Pós-graduação em Letras (PPGL) e do Mestrado Profissional em Letras em Rede Nacional (ProfLetras) da Universidade Federal do Tocantins, Campus de Araguaína. E-mail: luiza.to@uft.edu.br
} 


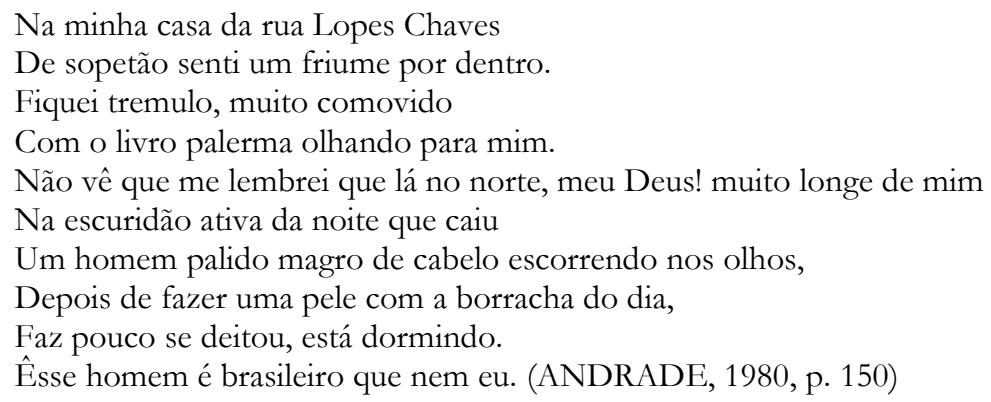

No poema, Mário evoca duas espacialidades distintas, a do aqui, de onde fala o narrador, situado no espaço tópico São Paulo, rua Lopes Chaves, na escrivaninha onde inicialmente o sujeito se encontrava com o livro na mão; e a do lá, onde se situa um outro sujeito sobre o qual se põe a refletir. Por uma ruptura, um acontecimento motivado por uma súbita lembrança ("sopetão" a produzir o "friume"), o primeiro passa a divagar sobre o outro, aquele situado no espaço do lá, do muito longe, no norte, ocupando-se de outros afazeres ("Depois de fazer a pele com a borracha do dia").

Tudo então nos versos concorre para acentuar a diferença de modos de viver e trabalhar (fazer intelectual versus fazer braçal), de ser e de existir, definindo-se a partir das noções da proximidade ou de distância a partir de um ponto de referência (o aqui, de onde fala o enunciador). Essa diferença, no entanto, é apagada por uma súbita conclusão, a de que comungam de uma mesma "brasilidade": "Esse homem é brasileiro que nem eu". O poema parece então encerrar-se como uma espécie de revelação: se esse dizer remete à esfera do já sabido, agora parece justificarse pela dimensão do sentido, haja vista que faz entrever nessa espécie de exclamação um sujeito que sente a irmandade do outro, ainda que não apagadas a distância que os mantém em disjunção e as diferenças inicialmente ressaltadas.

Principiamos nossa fala pelo poema modernista porque ele nos leva a refletir sobre alguns aspectos relativos à questão da identidade e da espacialidade que gostaríamos de salientar. Do ponto de vista identitário, deve-se compreender que tanto a semelhança quanto a diferença são sempre resultantes de uma produção, uma construção que engaja sujeitos historicamente situados (LANDOWSKI, 2002). Não há, nesse sentido, uma identidade dada pela natureza, inequivocamente, marcando o pertencimento do sujeito, mas efeitos de um complexo imaginário social e historicamente produzido e compartilhado aliado a processos ideológicos que lhe garantem adesão.

No caso de uma certa noção de brasilidade, que nos homogeneizaria apagando ou relativizando as diferenças e as distâncias, esta não se daria fora dos quadros da história ou da história dos discursos. O sujeito que enuncia o faz não a partir de uma apreensão particular e exclusiva, mas atravessado pelas filiações discursivas, concebida a Nação enquanto uma totalidade como uma "comunidade imaginada": "... é imaginada como comunidade porque, sem considerar a desigualdade e a exploração que atualmente prevalecem em todas elas, a nação é sempre concebida como um companheirismo profundo e horizontal" (ANDERSON, 1989, p. 16).

Não se trata, nessa direção, de pensar tão somente numa construção particular e subjetiva de um eu que subitamente se põe a categorizar o mundo, mas de considerar o modo como se compartilham discursos que concorrem para definir o caráter de relação com a alteridade sob a perspectiva da igualdade ou da diferença, da irmandade ou do estranhamento. Para os modernistas, dentre os quais se situa em lugar consagrado Mário de Andrade, importava salientar a semelhança e a irmandade. Num Brasil anos mais tarde, sob a sanção negativa da mídia a propósito dos resultados da reeleição de Dilma Rousseff para a presidência da República, importava evidenciar a distinção, o que nos faz diferentes e inconciliáveis, a justificar que de novo viessem à tona rancorosos discursos separatistas e encontrasse abrigo o regime da segregação, conforme pretendemos 
apontar na análise dos diferentes mapas que traduziam em imagens os resultados da votação de 2014.

Landowski (2002) discute o regime de segregação sob a perspectiva do caráter processual, considerando uma disjunção que ainda não se completou, a partir de uma fissura que age no sentido de separar o que há pouco fora conjunto, seja do ponto de vista real ou ao menos imaginado. A segregação corresponde, assim, ao momento em que "as forças centrífugas que são o seu motor" ainda não chegaram ao final, coexistindo ao lado de forças contrárias, as de coesão. Ainda segundo o autor, para que o status de desigualdade adquira sua legitimidade e a apartamento se complete, incidindo sobre a exclusão, é necessário contar não apenas com a adesão do grupo que a impõe, como ainda contar com as forças do grupo que a ela é submetido, como numa espécie de quasecumplicidade (LANDOWSKI, 2002, p. 19). A diferença é, pois, de um ou outro modo, assumida por ambos os lados e o que antes era irmandade agora é compreendido como irreconciliável estranheza.

É da segregação que trata um texto bem recente, assinado pelo movimento separatista São Paulo Livre, responsável pelo blog saopaulolivre.org. Trata-se do post publicado em uma rede social, o Facebook, em 27 de fevereiro de 2017:

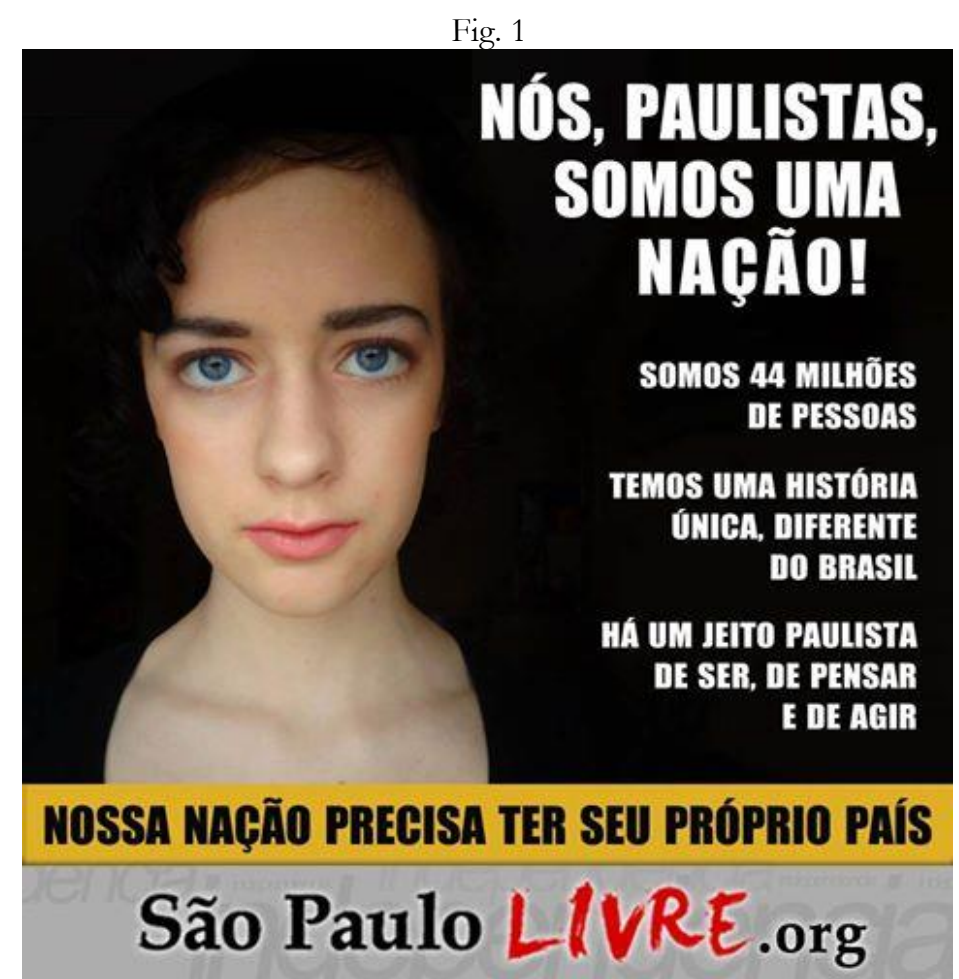

Post disponível em https://www.facebook.com/movimentoSPL/, publicado em 27 fev. 2017.

Junto ao cartaz (Fig.1), encontra-se um texto de caráter dissertativo que tem como principal argumento a defesa da identidade paulista como singular em relação a do restante país a ponto de justificar sua independência. Seguindo a perspectiva de Landowski (2002) a respeito da segregação, vemos que a argumentação visaria, assim, a minar as forças de coesão que ainda persistem e garantir a adesão de um "nós" (paulistas) aos propósitos separatistas.

A negação de pertencimento ao Brasil se dá já pelas próprias construções linguísticas nesse texto: não se fala ali em algo como um "restante do Brasil", mas de um Brasil como uma exterioridade sem qualquer identidade em comum além da língua com relação à "nação" São Paulo: "São Paulo teve uma história colonial muito diferente do Brasil (...)". Para isso se vale de pretensos argumentos históricos que comprovariam a singularidade dada desde o período colonial e que 
conformariam um “jeito paulista de ser, de pensar e de agir", como já acentuado na cartaz. Se no texto de Mário a certeza da irmandade enfraquecia o efeito das diferenças e das distâncias, no post publicado junto ao cartaz da Fig. 1, a diferença se caracteriza euforicamente para marcar a superioridade de um "nós" frente aos outros.

Nós, paulistas, somos culturalmente diferentes. Não se trata de raça ou etnia, mas sim de
cultura. Há uma cultura paulista, que veio de uma história paulista única e diferente. E
essa cultura pertence aos 44 milhões de paulistas que aqui vivem, tenham estes nascido
em São Paulo ou se adaptado à nossa cultura paulista. O fato é que não dá para negar
mais - somos um nação a parte. E por isso, queremos ter nosso próprio país - um país
menor, melhor, mais rico e mais justo - um país chamado São
Paulo! \#SPLivre\#OBrasilNãoDeuCerto

Embora não seja traduzido mais concretamente em que constitui o "jeito" peculiar do paulista, é assim considerado pelo enunciador aquele que lá nasceu ou se adaptou à "nossa cultura". Em termos landowskianos, essa adaptação corresponde ao regime da assimilação, que acaba por se caracterizar como uma outra forma de exclusão do diferente, na medida em que toda diferença do outro deve ser apagada em função dos interesses identitários do grupo de poder: "Como se vê, assimilação e exclusão não passam, em definitivo, de duas faces de uma única e mesma resposta à demanda de reconhecimento do dessemelhante: 'Tal como se apresenta, você não tem lugar entre nós"” (LANDOWSKI, 2002, p. 10).

Aliando-se aos trabalhos de Landowski os conceitos de triagem e de mistura advindos da semiótica tensiva, Barros $(2009,2011,2016)$ vai organizando uma sintaxe dos discursos de intolerância, compreendendo-se como sintaxe a identificação das regularidades que circunscrevem o modo de funcionamento dos discursos intolerantes. São concebidos como intolerantes aqueles discursos que se inscrevem sob o regime da segregação, quando a diferença do outro não é então admitida como aceitável. A ideia de nação pressupõe a possibilidade da mistura, a admissão da diferença, o respeito entre os que estão no espaço do "aqui" e dos que estão do espaço do "lá". A triagem, ao contrário, prevê a supervalorização da distinção, tendo como efeito a separação.

Nos termos dessa abordagem teórica, triagem e mistura correspondem a duas grandes operações da sintaxe extensiva, relativa ao "estado de coisas" (ZILBERBERG, 2011). A mistura corresponde aos processos de mestiçagem, de heterogeneidade, que compreende os "valores do universo" enquanto a triagem remete aos "valores do absoluto", consistindo em seleções que correspondem a processos sucessivos de "pureza", num projeto de redução da heterogeneidade. Levada a extremos, serve no plano das práticas aos discursos de ódio e intolerância, que prescrevem, por exemplo, a morte do dessemelhante. Para citar um caso recente ( 15 de novembro de 2016), temos o assassinato de um jovem estudante de matemática da UFG, porque o pai se recusava a aceitar suas posições políticas. Guilherme da Silva Neto era um dos milhares de estudantes engajados nas ocupações de universidades como forma de protesto contra as políticas empreendias pelo Governo Temer em relação à educação ${ }^{4}$.

Do ponto de vista de uma narrativa, Barros (2009) inscreve os discursos da intolerância na fase da sanção, aquela em que o sujeito destinador avalia negativamente a performance do outro, o destinatário, como que mediante uma quebra de contrato entre os sujeitos:

Em relação à narrativa, elaborou-se a hipótese de que o discurso intolerante é, sobretudo, um discurso de sanção aos sujeitos considerados como maus cumpridores de certos contratos sociais (de branqueamento da sociedade, de pureza linguística, etc.) e que, portanto,

\footnotetext{
${ }^{3}$ Disponível em:

https://www.facebook.com/movimentoSPL/photos/a.1732684196957716.1073741827.1732658630293606/2274 508892775241/?type=3\&theater, acessado em 13 mar. 2017.

${ }^{4}$ Cf. http://jconline.ne10.uol.com.br/canal/mundo/brasil/noticia/2016/11/16/pai-assassina-filho-e-se-mata-aposbriga-por-ocupacoes-estudantis-260485.php, acessado em 16 nov. 2016.
} 
devem ser reconhecidos como pretos ignorantes, usuários de lingua incorreta, indios bárbaros, judeus exploradores, árabes fanáticos, e punidos (com a perda de direitos, de emprego, com a morte). Concebida a narrativa dessa forma, a intolerância dos discursos encontra sua justificativa.

A narrativa intolerante deve ser entendida, portanto, como uma narrativa de ruptura de contratos entre destinador e destinatário. O destinador propõe um contrato, por exemplo, de branqueamento da população ou de pureza da língua, e considera que o destinatário - os negros, certos imigrantes, os que escrevem ou falam "mal" - não cumpriu esse acordo e merece, portanto, sanção negativa. O destinador é, assim, o sujeito do poder que julga e pune o destinatário em falta. (BARROS, 2009, s/p)

No contexto das eleições presidenciais, a polarização entre dos dois candidatos, representando opções mais à esquerda ou mais à direita confluiu para o recrudescimento das oposições de classe social (mais ricos versus mais pobres) ou de região (Norte versus Sul/Sudeste, ainda que os resultados evidenciem a ampla votação que Rousseff obteve nos Estados de Minas Gerais e Rio de Janeiro).

Os sancionadores - que atualizam os discursos intolerantes - apresentam-se, pois, como os que se colocam como destinadores inconformados com a performance indevida do outro, os destinatários. Para isso, é necessário compreender que essa perspectiva só é possível mediante uma assimetria de papéis actanciais: é o destinador quem orienta para um dado fazer, quem tem condições de fazer fazer, e quem se apresenta posteriormente como o que pode agir como julgador, sancionador. Ao mesmo tempo, a culpa pela ruptura da "comunidade imaginada" é relacionada ao outro, como se pode ler no "Blog do Noblat": "O país sai partido ao meio - e a maior culpa cabe ao PT com a política do 'nós' contra 'eles"”

Em seu $b \log$, Noblat defende que a separação se deu por obra do Partido dos Trabalhadores, que teria posto fim à unidade nacional. Para isso, ilustra seu post intitulado "Viva o povo brasileiro" com a reprodução de uma tela da artista Tarsila do Amaral, Operários (1933), como quem pretende confirmar a unidade dos trabalhadores, ou do "povo brasileiro". Deixa, contudo, explícita desde o início a certeza da cisão, como um já dado: "o país sai partido".

Reproduzido seu texto num outro site, o Nordeste Notícias, a imagem que precede o artigo confirma a separação entre norte e sul. $\mathrm{Na}$ imagem, uma grossa linha horizontal em zigue-zague atravessa o mapa do país, forma recortada da bandeira nacional (Fig. 2):

Fig. 2

\footnotetext{
${ }^{5}$ Disponível em: http://noblat.oglobo.globo.com/meus-textos/noticia/2014/10/viva-o-povo-brasileiro.html. Acesso em 23 mai. 2017.
} 


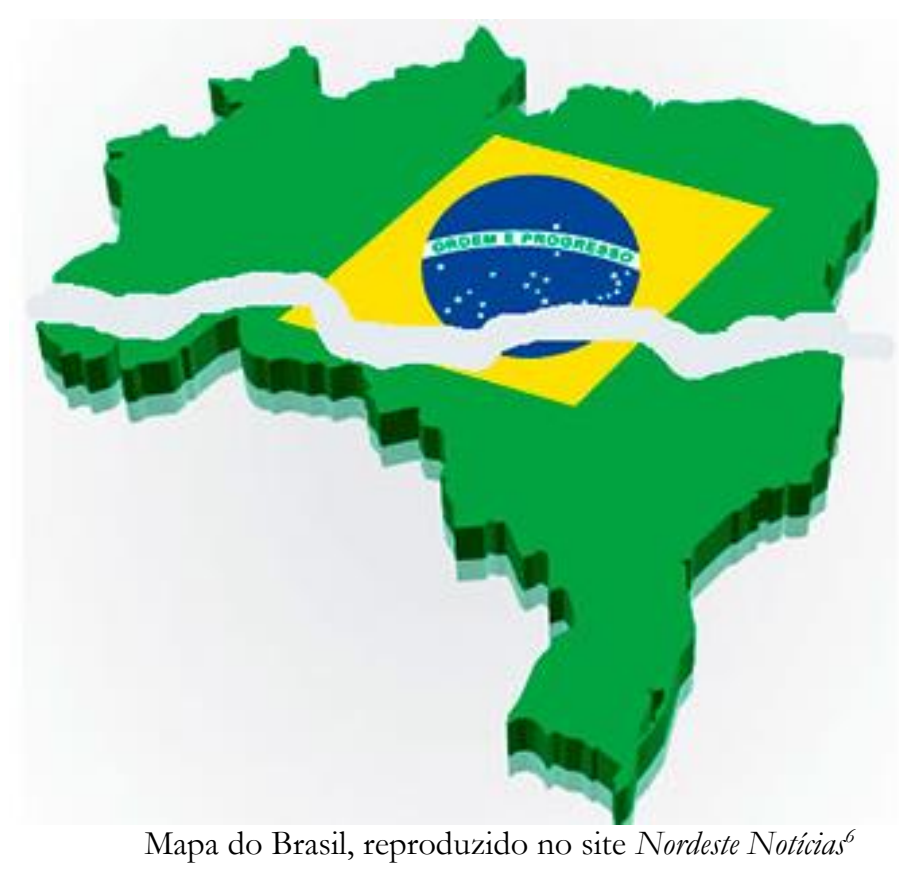

Ali também a culpa da separação é atribuída ao PT, o que se enuncia desde o título, anteposto ao de Noblat: "O PT rachou o Brasil".

Num artigo de opinião produzido poucos dias depois e comentando a intolerância que se avolumava nos discursos dos inconformados com as urnas, Pichonelli confirma o raciocínio de Barros, quando o intolerante (na situação de vencido) desqualifica o outro a partir do que corresponderia a suas "faltas", como a de julgar o outro cego por falta de "instrução" ou ignorância:

Em um país como o Brasil, onde o privilégio ao nascer e hegemonia política e econômica foram sinônimos ao longo da história, a ascensão de determinados grupos antes subjugados têm produzido todo tipo de ofensa ao chamado "individualismo democrático". Sobram patadas sobre pobres, gays, lésbicas, negros, "comunistas", mulheres. Um exemplo foram as manifestações de ódio contra a população nordestina, onde o PT conquistou muitos votos. A repulsa chega com todos os disfarces, mas pode ser identificada, por exemplo, quando um ex-presidente da República atribui um resultado adverso (para ele e os seus) à cegueira coletiva dos "menos instruídos". (PICHONELLI, 2014, s/p)

Gays, mulheres, lésbicas, negros, comunistas, pobres representam aqui as minorias do ponto de vista do poder e dos privilégios reunidos num único bloco a merecer a "repulsa" de sujeitos como um não expressamente identificado - "ex-presidente da República" - mas intolerante sujeito.

\section{Mapas da votação na eleição presidencial de 2014, segundo turno}

Os primeiros mapas que trouxeram os resultados da votação em segundo turno para o cargo de presidente da república partiam o país ao meio, imediatamente tendo como efeitos a multiplicação de impropérios nas redes digitais por parte daqueles que se enunciavam como "nós" em relação aos "outros", os de lá, do Norte e do Nordeste. O Brasil não é então sentido como uma

${ }^{6}$ Disponível em: https://nordestenoticias.wordpress.com/2014/10/29/pt-rachou-o-brasil/. Acessado em 23 mai. 2017. 
totalidade, mas como cindido, marcada a distinção nos mapas as zonas do azul (áreas de eleitores de Aécio) e do vermelho (dos eleitores de Dilma).

Não há, porém, uma uniformidade das representações, o que se justifica pela multiplicação de perspectivas que se anunciam a partir dos resultados, o que põe em questão a perspectiva do enunciador que traduz sua presença por procedimentos acessórios já que um mapa supõe resguardar-se dos indices específicos que poderiam remeter à instância da enunciação - para nos valermos aqui dos termos empregados por Benveniste (1989, p.84). É certo que Benveniste faz essa distinção considerando o aparelho formal da língua, mas fazemos uso de uma extensão desses termos para a análise das diferentes traduções dos dados em mapas, uma vez que elas implicam também uma práxis enunciativa.

Se observarmos o "Mapa Interativo" da Folha de São Paulo (Fig. 3), veremos que as nuances de gradação de tons de vermelho e azul remetendo aos detalhes da votação só ficam visíveis quando o internauta seleciona sua cidade e o Estado. Nesse caso, à direita encontra-se o mapa da votação no Estado de São Paulo.

Fig. 3

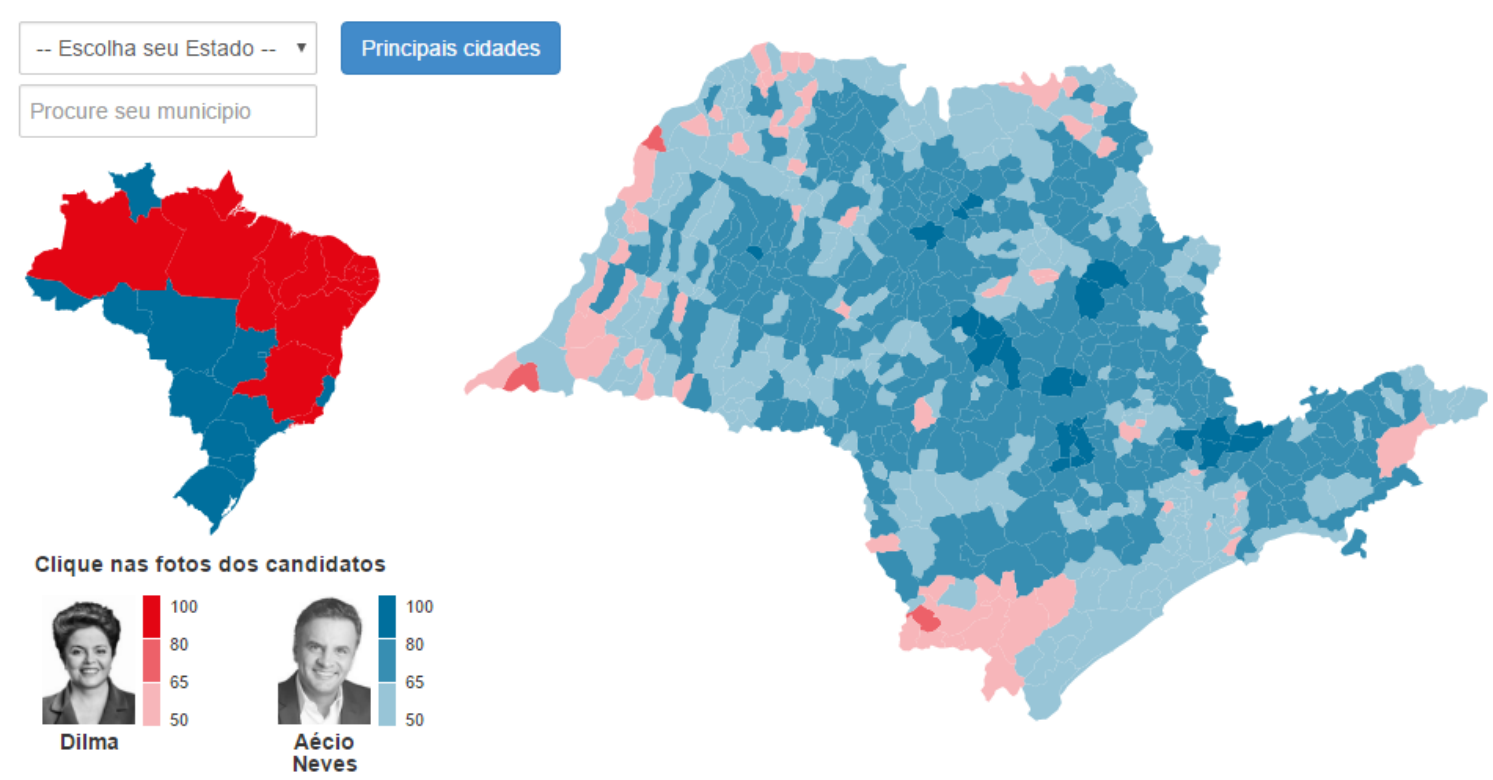

Mapa Interativo do jornal Folha de São Paulo ${ }^{7}$

Do ponto de vista da "segregação", o mapa desse jornal seria o que mais representa a divisão do país do ponto de vista político e ideológico naquele dado momento. Não há gradações, optando-se pelo emprego de cores primárias, sem nuances, organizando-se a oposição espacial entre os lugares do vermelho e do azul. O vermelho situa-se na metade superior, com pequena intromissão na metade inferior representada por uma curva à direita como se Rio de Janeiro e Minas Gerais fossem ali representados como extensões da faixa que cobre o Nordeste). O azul situa-se monolítico, na parte mais ocidental, na metade inferior. Cindido, o país é então traduzido como dois, em posições de oposição e ausência de conciliação.

Uma resposta ao mapa reproduzido pela Folha de São Paulo aparece no blog de Thomas Conti (Fig. 4) em 27 de outubro de 2014. Segundo informações ali presentes, seu trabalho contou com mais de 40 mil compartilhamentos e reprodução (não reconhecida) pelo jornal Folha de São Paulo.

\footnotetext{
${ }^{7}$ Disponível em: http://eleicoes.folha.uol.com.br/2014/2turno/mapainterativo/. Acesso em 16 nov. 2016.
} 
No blog, o autor explicita os procedimentos técnicos que lhe possibilitaram a elaboração de seu desenho (mapa à direita) que responde ao primeiro, à esquerda e que, segundo o autor, estaria servindo às manifestações de ódio e segregação. Temos, portanto, evidenciado o caráter responsivo - um mapa que responde ao outro; um enunciado que responde a um primeiro e também uma sanção. Em vez de sancionar os resultados da eleição, como se dá com muitas declarações nas redes sociais, o que Conti faz é rejeitar a opção primeira da Folha. Ao declarar "Menos ódio, por favor", a solicitação incomum a um tipo de reprodução de resultados estatísticos projeta no enunciado um enunciador de primeira pessoa, que se dirige pelo verbo no imperativo a um tu específico - aquele que ecoa o ódio.

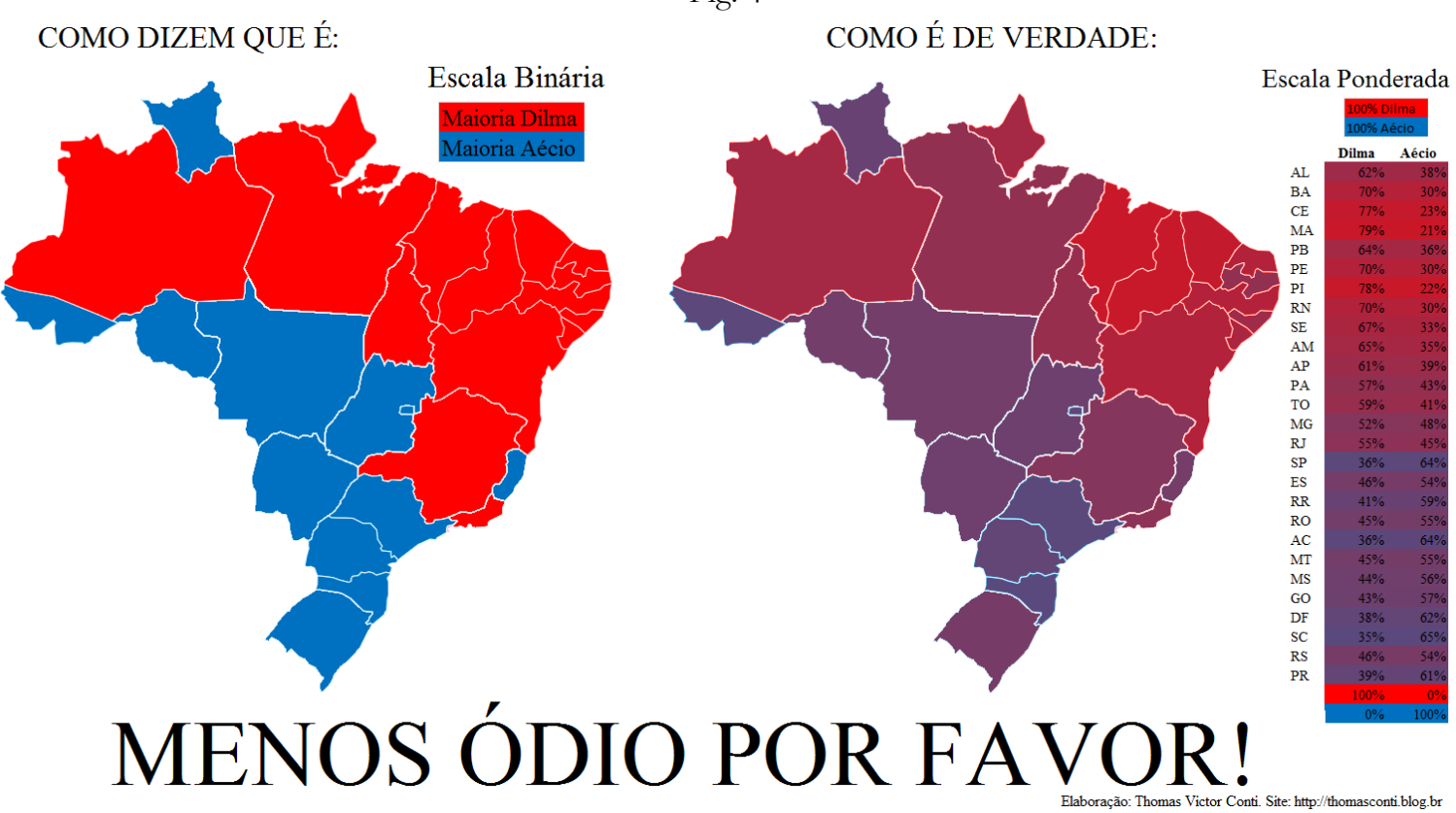

Mapa de Thomas Conti (2014) 8

Conti também esclarece que as representações levam em conta as diferentes escalas, sendo o primeiro mapa construído com a escala binária e o segundo com a escala ponderada. Trata-se, portanto, de uma escolha enunciativa que evidencia os efeitos que se pretende produzir no enunciado. Para explicitar os mecanismos mobilizados para a produção de seu mapa, Conti declara:

Usando o Excel 2013, computei o percentual de votos válidos de cada candidato em uma tabela. Nas versões mais novas, o Excel tem um recurso chamado Formatação Condicional que permite ao programa colorir automaticamente tabelas a partir de uma instrução. Usando esse recurso, selecionei o vermelho básico para $100 \%$ de votos em Dilma, e o azul básico para 0\% de votos em Dilma. Depois fiz o contrário para a coluna do Aécio: $100 \%$ de votos nele é o azul básico, e $0 \%$ de votos nele é o vermelho básico. Feito isso, todos os valores intermediários são coloridos automaticamente pelo excel, formando uma cor que reflete precisamente o grau de distância entre $0 \%$ e $100 \%$ nessas escalas. $\mathrm{O}$ fato de as duas colunas terem precisamente a mesma coloração atesta a precisão do programa. (CONTI, 2014, s/p)

\footnotetext{
${ }^{8}$ Disponível em: http://thomasconti.blog.br/2014/contra-o-preconceito-o-resultado-ponderado-das-eleicoes-porestado/. Acessado em 16 nov. 2016.
} 
O autor propõe, assim, relativizar a oposição inicial e o que ela implica quanto aos efeitos da segregação. Vermelho e azul então se mesclam, em diferentes gradações que embaralham ("como é de verdade") a diferença inicial ("como dizem que é").

Devido ao enxame de declarações preconceituosas vergonhosas que invadiu o Facebook depois de apurados os votos, acho bom as pessoas terem em mente que não apenas estão propagando um discurso de ódio tacanho e lastimável, como ainda estão com uma visão completamente equivocada da realidade deste país!

Os gráficos que foram veiculados distorcem o cenário eleitoral: dezenas de milhões de nordestinos não votaram na Dilma, dezenas de milhões do sudeste não votaram no Aécio! Não adianta ficar propagando ódio contra esse ou aquele grupo, venceu quem teve o maior número de votos ENTRE 144 MILHÕES DE ELEITORES. (CONTI, 2014, s/p)

Se o mapa aparece sob efeito de escolhas que são muitas vezes obscurecidas, Conti se apressa por esclarecer a opção de recursos que guiaram a elaboração a reprodução e, ao mesmo tempo, analisa as duas produções, explicitando sob a perspectiva de uma debreagem actancial enunciativa, que há um eu que escreve e desenha "seu mapa", com sua tradução particular dos números.

Fig. 5

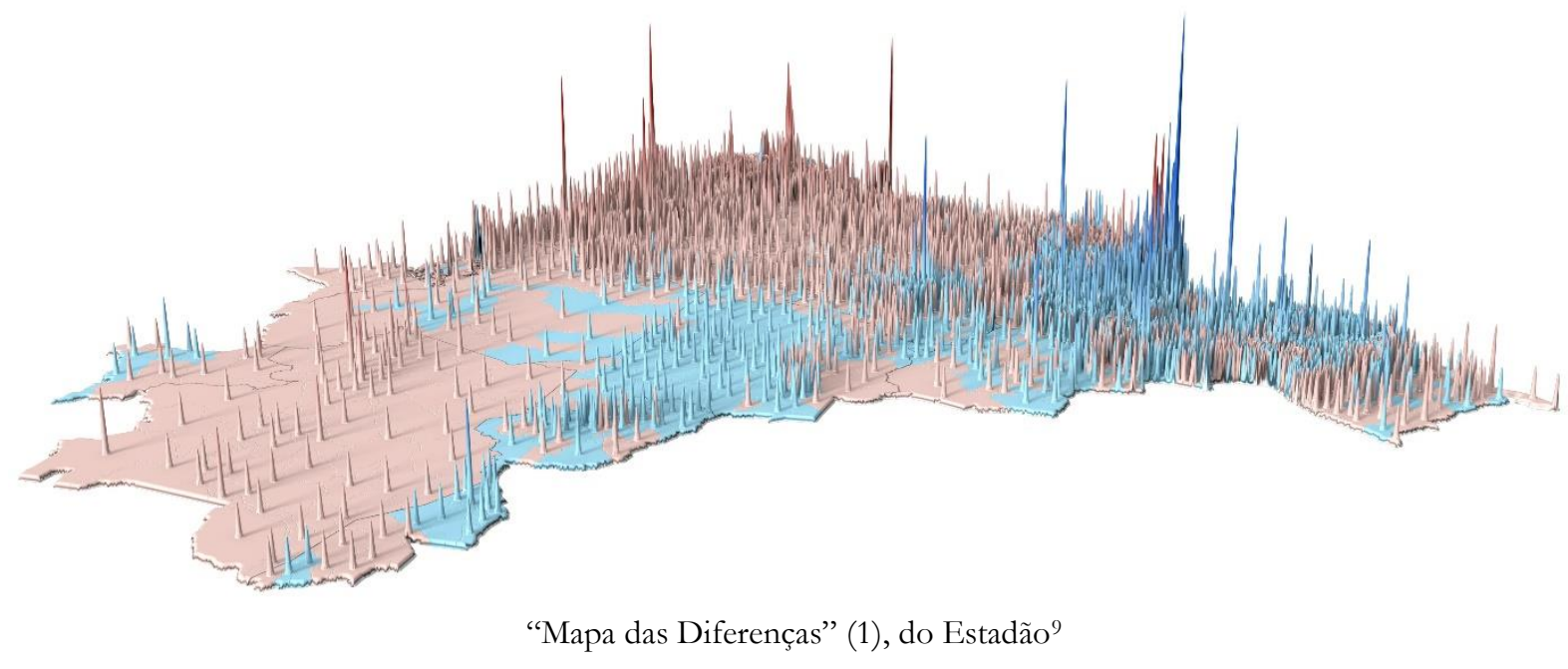

Fazendo uso de outras escalas, o Estadão traz um mapa de efeito tridimensional e móvel que vai girando e põe em evidência, em cada parada breve, uma das regiões do país, a que se somam pequenas caixas de texto que trazem dados numéricos e porcentagens relativas à votação. No gráfico, com picos coloridos em formato de cones longilíneos, indica-se a maior ou menor incidência dos votos dos candidatos pelo emprego das gradações de azul e rosa.

Fig. 6

\footnotetext{
${ }^{9}$ Disponível em: http://blog.estadaodados.com/category/eleicoes-2/eleicoes2014-eleicoes-2/, acessado em 16 nov. 2016.
} 


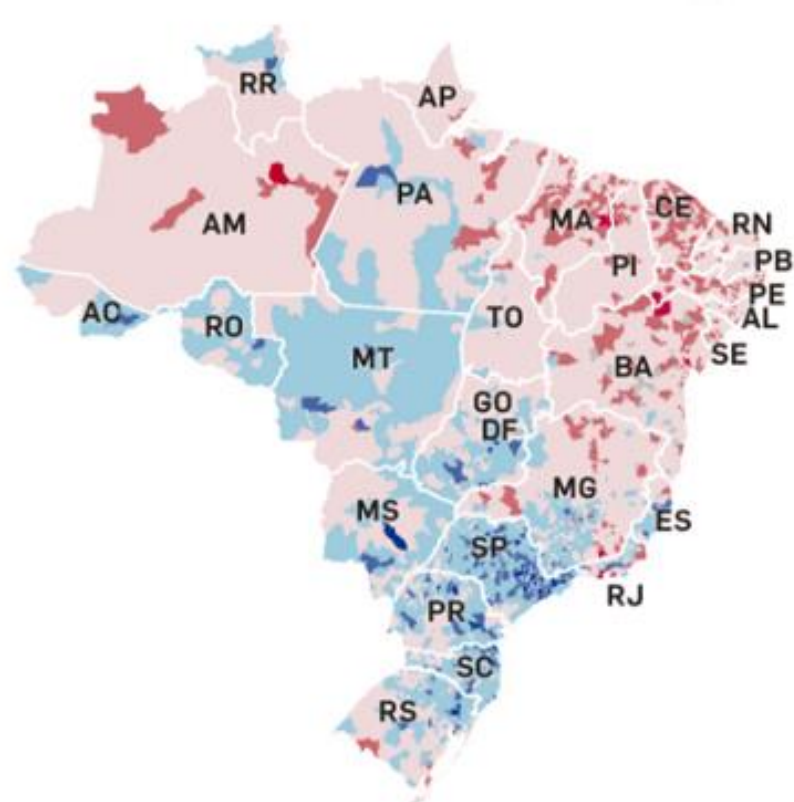

Mapa das Diferenças (2), do jornal O Estado de São Paulo (Estadão) ${ }^{10}$

Além dele, o jornal publica um segundo infográfico (Fig. 6) com legendas colocadas ao lado e que informam a respeito das gradações de cor em relação que correspondem em intensidade ao número de votos obtidos pelos candidatos (mais votos, mais escuro o tom e vice-versa). Sob o mapa há ainda uma nova legenda: "Detalhes da votação no segundo turno em cada município brasileiro. A intensidade da cor indica o maior número de votantes no candidato à presidência".

Com as indicações das capitais em caixa alta e cor negra, as linhas brancas dividindo as regiões, as gradações de tons róseos e azuis, o mapa do Estadão enuncia mais a heterogeneidade que os anteriores, mais embaralhamento das oposições e efeito de indistinção, ainda que o anúncio no título da página - "Mapa das diferenças" - pudesse corroborar a perspectiva segregacionista das assumidas por outras enunciações. A legenda que explicita a opção metodológica relativa ao desenho corresponde a uma debreagem actancial enunciva e seu efeito de objetividade, mas a própria explicitação dos mecanismos mobilizados para a produção do mapa indica uma escolha anterior ao resultado demonstrado.

\section{CONSIDERAÇÕES FINAIS}

Os modos de representar os números da eleição não são indiferentes aos efeitos produzidos nos leitores/espectadores que, na condição e eleitores, tinham em mãos documentos para analisar e posicionar-se quanto ao processo. Esconder as nuances, traduzindo a divisão, foi a opção política e ideológica que serviu para sancionar negativamente os eleitores do norte. As respostas a essa opção não tardaram a produzir resultados nas redes sociais e nas bocas de muitos pelo país, em alguns casos ganhando os espaços da grande mídia nacional.

Fig. 7

${ }^{10}$ Disponível em: http://infograficos.estadao.com.br/politica/resultado-eleicoes-2014/. Acesso em 16 nov. 2014. 


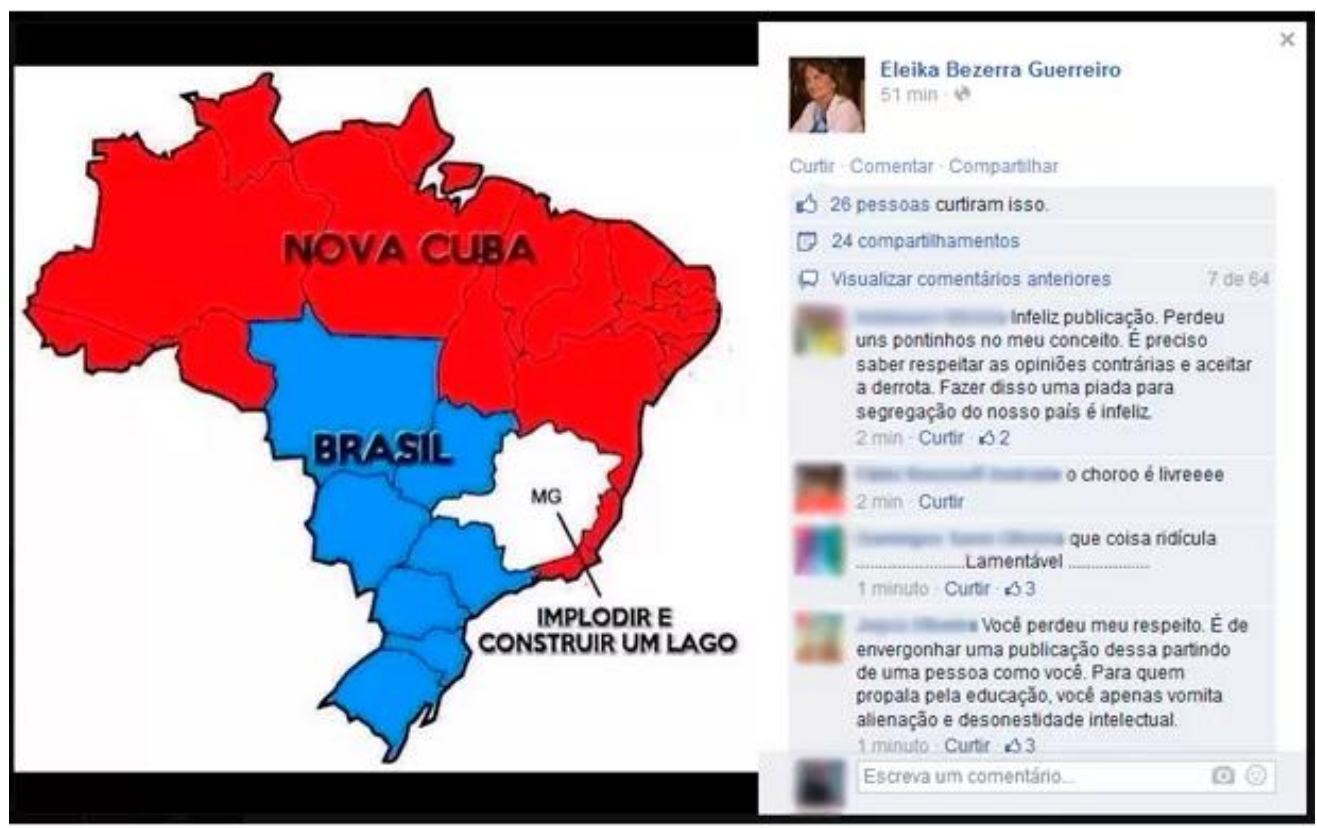

Reprodução de postagem da vereadora pelo site G1, em 27 out. $2014^{11}$

Um exemplo dessa reação pode ser lido no mapa compartilhado pela então vereadora da cidade de Natal, Eleika Bezerra Guerreiro em sua página pessoal no Facebook. A postagem posteriormente apagada depois de protestos de eleitores traz ali a expressão de sua rejeição ao resultado das urnas, ao circunscrever o espaço do Brasil ao dos Estados que majoritariamente votaram no candidato Aécio Neves. A região em vermelho é então nomeada como Nova Cuba, numa alusão aos votos à esquerda, com eleição da candidata petista. O Estado de Minas Gerais, que também teria sido responsável pela vitória de Dilma Rousseff, seria então implodido, como uma espécie de não-lugar.

Conforme depoimento transcrito no site G1, que reproduziu o post da vereadora, os preconceitos são por ela atribuídos aos outros, sem reconhecer o ódio separatista na sua postagem, inclusive por propor o desparecimento de todo um Estado brasileiro.

"Infelizmente nós saímos de um pleito em que muitos preconceitos foram abordados e disseminados. Há até um certo maniqueísmo entre etnias e condição social. Se você é de um, é bom. Se é de outro, é mal. Não tinha nenhuma intenção de ser separatista", afirmou a vereadora em entrevista à Inter TV Cabugi. (Site G1, em 27 out. 2017)

Como vereadora de uma das capitais do Nordeste, Guerreiro ecoava as vozes indignadas das regiões mais ao sul, pondo-se fora do que designava como Nova Cuba. Não se reconhece como "separatista", mas reproduz com humor suspeito a sua perspectiva de divisão do país. Não assume prestar-se a ecoar preconceitos, mas, embora nordestina, rejeita a posição dos eleitores de seu lugar. Atribui a outros o maniqueísmo, mas separa o país em dois, repercutindo o discurso segregacionista.

Há certamente muito a explorar sobre o contexto político brasileiro em uma crise que parece se aguçar a cada dia, fugindo à nossa capacidade de compreensão. Mas vamos aqui tentando estabelecer alguns caminhos para pensar este país. Ou ao menos pensar estes lugares de voz em disputa, produzindo diferentes sentidos para o ser brasileiro.

Nesse exercício de compreender o que é da ordem excessiva do acontecimento, pensamos que a semiótica, como teoria da significação, tem muito a contribuir para a análise dos textos que

\footnotetext{
${ }^{11}$ Disponível em: http://g1.globo.com/rn/rio-grande-do-norte/eleicoes/2014/noticia/2014/10/nao-sou-separatistadiz-vereadora-de-natal-apos-sugerir-divisao-do-brasil.html. Acesso em 23 mai. 2017.
} 
circulam nas redes, os regimes de interação entre coenunciadores, os gêneros híbridos com os quais nos confrontamos e, ainda, e os mecanismos específicos de enunciação expressos em textos como os mapas. Em momentos de crise, a luta se dá principalmente no plano dos discursos e do sentido.

\section{REFERÊNCIAS}

ANDERSON, B. Nação e consciência nacional. São Paulo: Ática, 1989.

ANDRADE, M. Poesias completas, v. 1. 6. ed. São Paulo: Livraria Martins; Belo Horizonte: Livraria Itatiaia, 1980, 216p.

BARROS, D. L. P. O discurso intolerante: primeiros estudos, 2009. Disponível em: http://diversitas.fflch.usp.br/node/2185. Acesso em 16 nov. 2016.

. A construção discursiva dos discursos intolerantes. In: BARROS, D. L. P. de. Preconceito e intolerância: reflexões linguístico-discursivas. São Paulo: Editora Mackenzie, 2011, p. 255-270.

Estudos discursivos da intolerância: o ator da enunciação excessivo. Cadernos de Estudos Linguísticos, Campinas, p. 7 - 24, jan./abr. 2016.

BENVENISTE, É. Problemas de linguística geral II. São Paulo, 1989.

CONTI, T. V. Contra o preconceito! O resultado ponderado das eleições por Estado. Disponível em: http://thomasvconti.com.br/2014/contra-o-preconceito-o-resultado-ponderado-das-eleicoespor-estado/. Acesso em 23 mai. 2017.

LANDOWSKI, E. Presenças do outro: ensaios de sociossemiótica. São Paulo: Perspectiva, 2002.

'Não sou separatista', diz vereadora de Natal após sugerir a divisão do Brasil. Disponível em: http://g1.globo.com/rn/rio-grande-do-norte/eleicoes/2014/noticia/2014/10/nao-souseparatista-diz-vereadora-de-natal-apos-sugerir-divisao-do-brasil.html. Acesso em 23 mai. 2017.

NOBLAT, R. Viva o povo brasileiro. Disponível em: http://noblat.oglobo.globo.com/meustextos/noticia/2014/10/viva-o-povo-brasileiro.html. Acesso em 23 mai. 2015.

PICHONELLI, M. "Nordestino não sabe votar". "Pobres merecem o que têm”. "Abaixo o Bolsa Esmola. "Vão pra Cuba. "Muda pra Miami”. Paraíba: Senso Crítico (online), 29 out. 2014. Disponível em: http://www.sensocriticopb.com.br/noticias/politica/nordestino-nao-sabe-votar-pobresmerecem-o-que-tem-abaixo-o-bolsa-esmola-vao-pra-cuba-muda-para-miami-matheuspichonelli/. Acesso em 16 nov. 2014.

ZILBERBERG, C. Elementos de semiótica tensiva. São Paulo: Ateliê Editorial, 2011.

Recebido em 21/08/2017

Aceito em 06/11/2017

Publicado em 19/12/2017 